\title{
مفاهيم في علم الجمال
}

\author{
فيصل الخراز 1 \\ كلية الآداب جامعة مصراتة
}
تاريخ التقديم: 08-09-2021، تاريخ القبول: 11-10- 2021، نشر إلكترونيا في 12-10-2021/2021 https://doi.org/10.36602/faj/2021.n.18.08

يتناول البحث موضوعات الفنون والجماليات، ويهدف إلى إيضاح تخصصات علم الجمال Aesthetics علوم الجماليات من شأنه صقل المواهب وتمكين الهواة والمهتمين من فهم واستيعاب المعاني والمضامين التي تمدف إليها الأعمال الفنية، باعتبارها مظهر من مظاهر التعبير التي يستخدمها الإنسان المبدع لتوصيل ما يحس به من مشاعر وانفعالات كامنة في وجدانه وتعجز اللغة عن توصيفها. كما يهدف البحث إلى دراسة قضايا الفن من النواحي الجمالية والنقدية التي غايتها بيان خصائص الجمال في الأعمال الفنية ومعرفة تقييمها وإصدار الأحكام الجمالية عليها. كما نستعرض العلاقة الجدلية القائمة ما بين الفن والدين والأخلاق ومدى تأثيرها على مستويات الإنتاج والإبداع الجمالي.

الكلمات المفتاحية: الأحكام الجمالية، الفنون الجميلة، غايات إستاطيقية.

F_alkharraz@misuratau.edu.ly ${ }^{1}$ 


\title{
Concepts in Aesthetics
}

\author{
Faisal Elkharraz \\ Faculty of Arts - Misurata University
}

\begin{abstract}
The research deals with topics of arts and aesthetics, and aims to clarify the art of Aesthetics disciplines and its importance in spreading aesthetic awareness and developing an aesthetic taste. The importance of studying the sciences of aesthetics will refine talents and enable amateurs and those interested to understand and comprehend the meanings and implications that art works aim at, as it is a manifestation of expression used by the creative person to convey what he feels from feelings and emotions latent in his conscience that language is unable to describe. We also review the dialectical relationship between art, religion and ethics and their impact on the levels of production and aesthetic creativity.
\end{abstract}

Key Words: Aesthetic Judgments - Fine Arts - Aesthetic Intent

1

قديماً ومنذ صوّر الله الإنسان، وأودع فيه الحواس، وأقر فيه العقل والتفكير، هيأه لأن

يقبل على كل جميل ويقدره، ويبتعد عن كل قبيح وينغره، وذلك هو النهج المستقيم والطبع

السليم، وتلك هي فطرة الله وسنته، ومن نعمه على الإنسان أن جعله يميز الجمال دوناً عن

غيره من سائر المخلوقات، فكلنا نحسه ونراه وهو يحيط بنا من كل جانب، حيث نجده

ظاهراً في لوحات الطبيعة الرائعة، وتلك المناظر الحنلابة، أو نلمسه ونحسه في باطن النفوس 
الخيرة والملهمة من هؤلاء الفنانين بمختلف أنماطهم واتجاهاةم التي تظهر على هيئة إبداع فني في الشعر أو الرسم أو النحت أو الموسيقى وغيرها من الفنون الرائعة الأخرى. ولكـن النـاس والمجتمعـات على مـر الزمان واختلاف المكان قـد يختلفون في تقدير الجمال والقبح، ويتباينون في إدراك معانيه، وذلك تبعاً لتأثير بيئاتم وأحوالهم وبتحاربمم وأيضاً عقائدهم وثقافاقم وعاداقم تقاليدهم المتوارثة بينهم، ولكن مهما يكن بينهم من تباعد أو خلاف في أحاسيسهم نحو جواهر الأشياء أو في أحكامهم العقلية حول مظاهر الجمال والقبح، فإننا دون شك نجد قاسماً مشتركاً يجمعهم في أصول الجمال. فقد يختلف الناس في أساليب تفكيرهم، وأنواع معارفهم وعلومهم كما يختلفون في فهم مقاييس الخير والشر، ومع ذلك لمم أصول كلية متشاهة في المنطق، وقواعد التفكير أو معايير معينة تحكم السلوك والأخلاق ومن ذلك فإنه ليس من الصعب على المفكرين إيجاد أصول جامعة يمكن الاسترشـاد بها وتطبيقها لتذوق ومعرفة وتحديـد الجمـال، إذ لابـد أن هناك علاقة بين المظاهر الجمالية وخاصية مشتركة تجمع هؤلاء الناس بمختلف أذواقهم. 1.1

لعل تلك الخاصية التي نسميها بالشعور أو الحس الجمـالي الذي ينتابنـا ويعترينـا

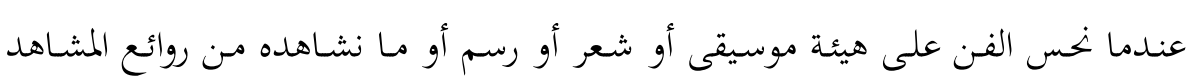
الطبيعية التي تثير مشاعرنا وتحرك ما في وجداننا جديرة بالاهتمام والبحث. وتأتي أهمية البحث مـن خلال تسليط الضوء ومعرفة الطبيعة العامة لهذا الشعور الجمالي الممتع الذي يبعث في تلك النفوس الراحة والانسجام، والتي قد تمر دون أن نعيرها اهتماماً أو نعطي لها بالاً. 
ورأيت مس المهمم لفت الانتباه إليها وفهم بواعثها وفلسفة جمالها، حتى نستشعر الجمال ونتعرف على ملامحه ومكنوناته عندما نتعرض له على كافة أنماطه وأشكاله المتنوعة. 2.1

واجه الفن عبر العصور منذ أفلاطون وأرسطو وتوما الأكويني وكانط وهيجل وحتى سـانتيانا وبرجسون وآخرين كثير غيرهم، واجهه مشكلة عـدم الثبـات في نسق واحسد، وأن الاتفاق مع ابتاه فكري معين يؤدي إلى خلاف وتناقض مع ابتحاهات أخرى، فهناك من يربط الفن بالأخلاق ومفكر آخر ينطلق من رؤى دينية أو غير دينية، وهل الفن مثالي أو مادي؟ وهل هذه المثالية ذاتية أم موضوعية؟ وما هي طبيعة الفكر المادي وما إلى ذلك وكان ذلك سبب في تأرجح رؤيـة الفن مـا بين هـا الفيلسوف وذاك المفكر، وصياغتهم لنظرياقم في الجمال وفلسفة الفن. وكانت الخلافات والمفارقات كبيرة، فنجد فيلسوفاً كبيراً له رؤية فلسفية أو مذهباً قوياً، ولكنه في ذات الوقت يتعارض مع فيلسوف آخر مناظر له ويخالفه الرأي تماماً في ما قدم له الحجة وأثبت صحته. ولعل هذا ما جعل التساؤل أو الإشكالية موضوعاً خصباً وهاماً تداوله الفلاسفة على مر العصور. 3.1 - عرض الآراء لبعض الفلاسفة حول مفهوم الفن والجمال. - - تحرير ماهية الجمال والتمييز ما بين الفن والجمال والعلاقة بينهم. - - التمييز ما بين الجمال الطبيعي والجمال الفني. - معرفة مقاييس الجمال وكيف يثير فينا الشعور بالارتياح. 
- - معرفة العوامل المؤثرة في التقدير الجمالي وصولاً إلى التقييم الجمالي وإصدار الأحكام الجمالية.

\section{( 4.1}

الدراسات الجمالية رغم أهميتها فإن المكتبات العربية تفتقر بشكل ملحوظ إلى كتب

ومؤلفات في مجال الفن والجمال وهذا بسبب البيئة والعوامل الاقتصادية بالمنطقة العربية وما تعانيه مـ أزمات وعدم استقرار وفقر مما يؤثر سلباً على الوعي الجمالي والإدراك الفني، وبالتالي فإن البحوث العلمية المختصة بالفن والجمال قليلة ونادرة وهذا ما يجعل الكفاية في هكذا مجال أو تخصص مفيد وعلى قدر من الأهمية.

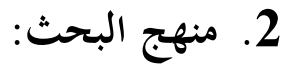

يرتبط منهج البحث بموضوع الدراسة، فقد اتبعت المنهج التحليل المقارن في محاولة لاستنتاج المضـامين الفلسفية المتعلقـة بموضـوع البحثث حتى يكـون عرضـها ضـمن سياق الدراسة وصولاً إلى الغاية أو الأهداف المنشودة.

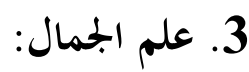

وإذا بدأنا من علم الجمال فهو أحد فروع الفلسفة، ويبحث هذا العلم في المسائل المتعلقة بوجود الأشياء الجميلة واستجابة الإنسان لهذه الأشياء ومدى تأثره بها، كما يبحث في طبيعة وقيمة الفن بوجه عام، وإصدار الأحكام الجمالية ويمكن أن نقول أيضاً أنه المجال الذي يتعامل مع وصف الظواهر الفنية والخبرة الجماليـة وتفسيرها وكل مـا يتعلق بدراسة الإدراك للجمال والقبح.

وبشكل عام فإن علم الجمال منذ القدم يعني دراسة الجمال في الفن والطبيعة أما حديثاً فقد اتسعت دائرة هذا المفهوم لتشمل دراسات عديدة من طبيعة التجربة الجمالية 
وطرق وأساليب التعبير الفتي وعملية الإبداع والتذوق الفني وهو مـا يسمى بسيكولوجية الفن.

وقد ميز الفيلسوف بيردسلي (*) مؤخراً في 1958 بين فرعين من علوم الجمال، الأول في مجال الجماليات الفلسفية أو فلسفة الجمال ويختص بدراسة معاني الجمال وخصائصها وأنواع الأحكام الجمالية. أمـا الثاني فهو علم الجمـال السيكولوجي ويختص بالجماليات من الجانب السيكولوجي أو علم النفس (عبد الحميد، 2001، ص

وبالتـالي فـإن هـذا العلم قـــ يجيـب علـى جملـة تســاؤلاتنا الـتي هـي مـن صـميم اختصاصـاته فهو يبحـث عـن معتى الجمـال والفـن ومـا هي علاقـة الشكل بالمضـمون في الأدب الفني؟ وما هو الدور المشترك الذي تقوم به كافة الفنون رغم اختلافها؟ وعلى ذلك فإن علم الجمال لا يبحث فيما إذا كان هذا الشيء مفيداً أو ضاراً، صادقاً أو كاذباً، خيراً أم شراً، فهو يبحث في الجمال ومقاييسه ونظرياته وفي الذوق الفني والأحكام الجمالية التي تنصب على الأعمال الفنية.

يعتبر علم الجمال من العلوم الحديثة وإن كان متداولاً منذ القدم، وإن أول من خصه بالبحث هو أبو الفلاسفة أفلاطون ومن بعده أرسطو وإن كان لكل منهم آراءه ونظريته الخاصة به واستمر الفلاسفة من بعدهم في دراسة هذه الظاهرة كعلم، من ضمن دراساتم الفلسفية للقيم الإنسانية الأخرى.

إلا أن هذا العلم لم يعلن عنه بشكل مستقل كعلم قائم بذاته إلاّ على يد الفيلسوف الألماني إسكندر بوبجارتن 1714-Alexander Boumgarten 1767، وهو من (*) مونرو بيردسلي Monroe Beardsley (1915-1985)، فيلسوف أمريكي، وأستاذ جامعي، ورئيس للأكاديمية الأمريكية لعلم الجمال. 
أتباع "الديكارتيين" وينتمي إلى مدرسة "ليبنتز "Leibinz، حيث أصدر كتابه "تأملات فلسفية" حول المسائل المتعلقة بالشعر في العام 1757، وتناول فيه دراسة الجمال تحت المسـمى الـذي وضعه وهـو "استطيقا" Aesthetices أي علم الجمـال وبـذلك أصبح الجمال يدرس كعلم يختص بتكوين الذوق وطبيعة الانفعال ويهتم بتحليل ظاهرة الجمال والخيال الفني وكل ما يتعلق بها (الديدي، 1981، ص.39). وقد أطلق عليه اسم علم الحساسية وعرفه بأنه نظرية الفنون الحرة، وأنه علم المعرفة الحسـية، ويهـتم بالنـواحي العمليـة ولـيس فقـط التأمـل النظـري، وأشـار إلى أن الفلاسـفة اليونانيين ميزوا بين موضوعات الإحساس والجمال وموضوعات التفكير، حيث أن رؤيتهم إلى موضوعات الإحساس أهـا لا تتطابق مع الأشياء المُذْركة بالعقل، لأن الأشياء التي لا تكون ماثلة بالفعل تسمى بالمتخيلات، ومن ذلك فإن موضوعات الفكر هي موضوعات المنطق بينما موضوعات الإحساس والجمال لها علمها الخاص بها وهو علم الجمال (بجاهد، (16.1980 صـ (19) وقد لاحظ وجود نقص في التقسيم الذي يتبعه الفلاسفة بوجود قوى عليا وقوى دنيا، وجعل المنطق كعلم يبحث في القوى العليا ووضع الإدراك الحسي كعلم يبحث في القوى الدنيا ثم جعل علم الجمال لكي يبحث في تقييم الإدراك الحسي الإنساني (أبوريان، (30.) (30) 1992 وبـذلك يرجـع لـه الفضـل في الاهتمـام بالدراسـات والأبحاث المتعلقـة بالجماليـات وضرورتا بالنسبة للفلسفة وأها يمكن أن تكون منهجاً علمياً قوياً منظماً. كمـــا اسـتعمل "كـــانط" E.kant (1724-1804) كلمـــة الاســتطيقا Aesthetics للمشاعر والأحاسيس، وتناول المصطلح بعمق وأكثر شمولية في كتابه "نقد ملكة الحكم" 
حيث تطرق إلى الأحكام التقديرية التي تتعلق بشؤون الجمال، وكان من أبرز ما جاء فيه أنه ميز بين الجمال الطبيعي والجمال الفني، فالأول وهو ما يعتبره الشيء الجميل، وهو من صنع الطبيعة ذاها ولا دخل للإنسان فيها، بينما الثاني وهو العمل الجميل الذي يكون من صنع الإنسان وإبداعه، وبالتالي اعتبر أن ما يمكن وصفه بالجميل يتواجد في الطبيعة بينما الجليل لا يمكن ملاحظته ورؤيته إلا في نطاق فكرنا.

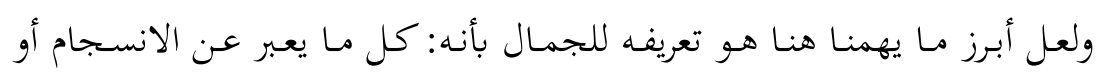
الاتساق والنظام وهذا هو قوام الجمال ومحط تقديرنا وإعجابنا في مجال الطبيعة، أما في مجال اللامتناهي فإن إعجابنا يرجع إلى الشعور بالروعة والجلال (Kant, 1790, P.79). وقد عُرِفِ علم الجمال بأنه العلم المتعلق بالشروط الخناص بالإدراك الحسي ويُعتبر هذا التعريف عام لأنه في القرن العشرين تحول التأكيد الخاص في هذا المجال من الاهتمام بالحاسة Sense إلى الاهتمام بالحساسية Sensibility ومن ذلك فإِها تعتبر التجسيد The الواضح للانفعـال في الفـن، ومـن هـذا السياق نجـد القـاموس الإنجليزي الجديد New English Dictionary في الطبيعة والفن (عبد الحميد، 2001، ص 18). والجدير بالذكر أن الشعور الجمالي أو موضوعات الجمال التي يختص بها علم الجمال أو فلسفته سـابقة على ظهـور هـذا المبحــث نفسـه، فالإنسـان فُطر على حسب الجمهال والإحساس به، فهو لم ينتظر إنشاء هذا العلم لكي يتذوق الجميل، ويصدر أحكاماً جمالية، فمن العادة أن المبحث يسبق الاسم ويكون أقدم منه بكثير قبل أن يتدرج ويتطور ليصبح علم معروف قائم بذاته، فحسب ما هو معروف فإن أي علم تصقله ثلاثة مراحل الأولى ما قبل تحديد تسمية هذا العلم، والثانية وهي ظهور التسمية أو المصطلح الخاص به، وهذا بمثابة الوعي الذاتي بهذا العلم، ومس ثم يدخل في المرحلة الثالثة التي يتم فيها تحديد العلم 
ودراسته ونقـده ومزاياه وأهدافه، ومـن ذلك فإن تحديد اسم أي علم يعني محصلة جهود عظيمة وبعيدة لتحديد معالمه وهذا التحديد لا يأت بطبيعة الحال في البداية وإنما عقب أي حقبة تاريخية (بجاهد، 1980، ص.15). ولعل أهمية هذا العلم واتساعه والرغبة في الإحاطة بمفهومه جعل الفلاسفة يعملون على إدراجه من ضمن العلوم الإنسانية تحت مسمى فلسفة الجمال أو علم الجمال. وعلم الجمال يهتم بنظريات الفلاسفة ويعتمـد على أبحاثهم وآرائهم في الجمـال وعلاقته بالإنسـان ويـدرس مشـاعر وإحساس الإنسـان وتأثره بالجمال وإبداعاته الفنية في ججالات الفنون المختلفة وتقييمها وإصدار الأحكام الجمالية عليها. ولذلك لا يتم تفسير هذه النظريات بغير الإشـارة إلى تاريخ الفنون على نحو مـا تقتضي باقي العلوم الأخرى مثل الفلسفة الأخلاقية التي تقتضي البحث في دوافع السلوك وغاياته أو المنطق الذي يقتضي البحث في تاريخ العلوم وطرق التفكير. ولقـد حـاول الفلاسفة الوصول إلى هـا الهدف وبتفسير الظـاهرة الجماليـة وتحديد تعريفاتما ومضموها واعتقد البعض أفا مقنعة على طريقة المنطقيين ولكن جانبهم الصواب في ذلك وأدركوا أغم أمام ظاهرة تستعصي على التعريف لأهما في مجال البحث الجمالي وهذا يعني أها في مجال الوجدان والشعور لا في مجال العقل والقضايا المنطقية (أبوريان، 1992، ص. (70) والجمال قد يدرك في الطبيعة كما يدرك في الفن، ولكن إذا ماكان من اليسير على الإنسان إدراك الجمال الطبيعي، فإن الجمال الفني على العكس من ذلك، إذ قد يصعب إدراكه في كثير من الأحيان، لأن ذلك يتطلب معايير ومهارات معينة يتوجب الإلمام بها ودراستها وتدريب إحساس الناس بهذا الجمال بواسطة الفن وعلومهه وهـذا على غرار مـا 
يحدث مع سائر العلوم الأخرى لمعرفة حقيقة الأشياء والموجودات التي تظهر بوضوح في علم الطبيعية وتتطلب تعليم وتدريب إدراكه للواقع بواسطة العلم. وبالتالي فإننا يمكن أن نطمئن إلى الآراء والدراسات المدونة والمتخصصة في تفسير الجمال مثلما نطمئن إلى نتائج المعرفة العلمية في فهم حقيقة الأشياء الموجودة في الواقع، وهذا مـا يدعونا إلى استعراض مفهوم الجمال لدى بعض الفلاسفة عل ذلك يوضح لنـا المفاهيم الأساسية لمذه الظاهرة.

1.3 إذا بحثنا في المعنى اللغوي فإننا نجد أن الجمال يعني الجميل، وفي اللغة الإنجليزية فإن الجمال يعني Beauty, Beautiful Beauté, Beau وفي اللغة الفرنسية فإنه يعني Bellus وهذا راجع إلى الأصل اللاتيني والجمال عند الفلاسفة كافة صفة تلحظ في الأشياء وتبعث في النفس سروراً ورضاً، والجمال هو أحد المفاهيم الثلاثة التي تنسب إليهم أحكام القيم وهي الجمال، والحق، والخير (صليبا، 1982، ص 407). وقديماً قال السوفسطائيون أنه لا يوجد جميل بطبعه، بل يتوقف الأمر على الظروف وعلى أهواء الناس، وعلى مستوى الثقافة والأخلاق في حين قال الفيثاغوريون أن الجمال يقوم على النظام والتماثل في الانسجام، كما وصف ديمقريطس أن الجمال هو المتوازن أو المعتدل في مقابل الإفراط أو التغريط، وربط الجمال بالأخلاق، في حين نجد سقراط يقول: "الجمال هو الشيء الذي يجيل كل الأشياء الجميلة جميلة" (أفلاطون، 1965، ص 99)، وربط الجمال بالخير والفضيلة والفائدة وقد سار على فجه تلميذه المخلص أفلاطون وإن 
كانت له رؤيته الخاصـة، فقـد اعتبر الجميل مستقلاًا عـن مبـدأ الشيء الذي يظهر فيـه، فالجمال الذي نشاهده في الأشياء ليس حقيقياً فما هو إلا خيال ومظهر للجمال الحقيقي المثالي في العالم المعقول عالم المثل العليا، فالجميل صورة عقلية مثل صورة الحق أو الخير، وإن كان تلميذه أرسطو وضع في كتابه "فن الشعر" تعريفاً للجمال من دنيا الواقع يتعارض مع

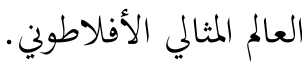

أمـا القـــيس "أوغسـطين" فكـان يــى أن الجمــال يقـوم في المختلـف، والتناسـب العددي، والانسجام بين الأشياء في حين يقول القديس "توما الأكويني": "إن الجميل هو ذلك الذي لدى رؤيته يسر" ومبعث ذلك أنه موضوع للتأمل عن طريق الحواس أو داخل

$$
\text { الذهن (عبد الحميد، 2001، ص ص 14-15). }
$$

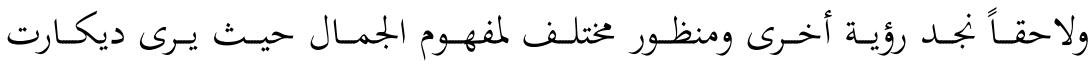

(15escarts (1650-1596) أن الجمـال مسـألة نسـبية في الحكـم الجمـالي وتقـديرنا للجمال فما يمكن أن نطلق عليه صفة الأجمل هو ما يروق وينال إعجاب العدد الأكبر من

$$
\text { حكم الناس (أبوريان، 1992، ص. 25). }
$$

ويأتي في مرحلة متقدمة عن ذلك شوبنهور 1788) A Schopenhauer-

1860) الذي يرى أن الجمال والفن أرقى وأعلى مستوى أو مرتبة ممكن أن يصل إليها الإنسان، ويرى أن العالم ليس سوى موسيقى تجسدت، وأن مفهوم علم الجمال عنده يرتبط بميتافيزيقاه المثالية (أبوريان، 1992، ص. 490). 
كمـا أن جـان مـاري جويو ${ }^{1}{ }^{1}$ الأجزاء وفقاً لغاية معينة ينطوي على نظام وانسجام وهذان صنوا الجمال. أما بول فاليري Paul Valiry فقد خرج عن المألوف برؤية فنية مختلفة، حيث قال: ولد علم الجمال ذات يوم من ملاحظة وشهية فيلسوف، ويعٌرف علم الجمال بأنه علم الحساسية (الصباغ، 2001، ص.38). وإذا مـا أردنا أن نخصل على تعريف مبـدئي وشمـلي فبإن هيجـل يقـول: "إن علم الجمال هو فلسفة الفن الجميل، إنه فلسفة الوعي الجمالي، وفلسفة للقدرة على الإبداع الأكثر صدقاً وجمالاً وفلسفة للتذوق الأكثر قدرة على الاستيعاب" (بجاهد، 1980، ص

وقد ساد التيار المثالي فلسفة الفن الألماني عامةً بعد كانط وهيجل، فنجد رؤية شوبنهور للجمال بأنه صفة للشيء الذي ييعث اللذة والمتعة في النفس بغض النظر عن أي فائدة، فهو يبعث على التأمل ويحقق نوع من السعادة الخالصة، فهو يعبر عن الشعور والإحساس النقي والعبقرية الفنية لدى الإنسان ويحرر العقل لبعض الوقت من الرغبة ويحقق تلك الصورة الخالدة تلك التي نادت بها المثل الأفلاطونية قديماً (الديدي، 1985، ص 17). ويعتبر جورج هيجل George Hegel هو صاحب الفضل الأكبر في ظهور علم الجمال بصورة جديدة، وقد تتابع اكتمال هذا العمل فيما بعد على يد هربرت ريد4 4 1 جان ماري جويو 1854 Jean Marie Goiao (1888)، فيلسوف وشاعر مهتم بالنظرية الجمالية ودورها في تطوير الجتمع. 2 بول فاليري Paul Valiry 3 جورج هيجل Goerge Hegel (1770-1831) ، فيلسوف ألماني من أهم مؤسسي المذهب المثالي والمنهج الجدلي. 4 هربرت ريد Herbert Read 
Formal الذي أطلق عليه اسم "علم الجمـال الصـوري Herbert Read Aesthetics

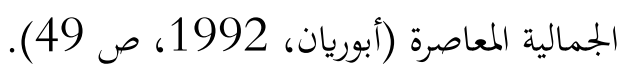

والأهم من ذلك هو أن الجمالية اتضحت معالمها بشكل واضح وصريح كمذهب

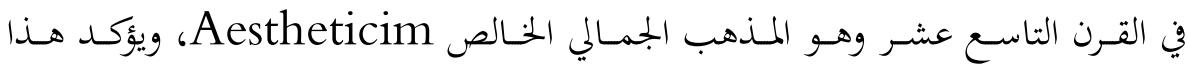
المذهب على أهمية واستقلالية الجمال في العمل الفني، وأن القيمة الوحيدة للعمل الفني هي القيمة الجمالية الخالصة ومـا هـا إلا امتداد لمذهب الفـن للفن الذي دعـا إليه الشـاعر والروائي الفرنسي (بتوفيـل جوتيـه) Gautier-1811 Theophile

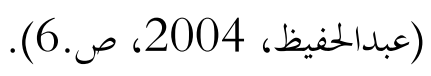

2.3

يقول كلايف بل "Clive Bell ${ }^{1}$ "أن لفظ جميل لا يشير بالضرورة إلى أية

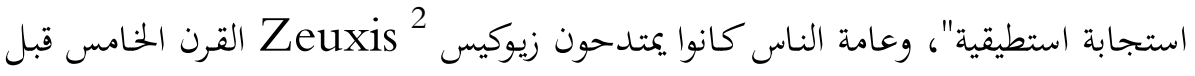

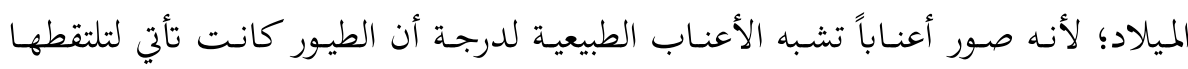
(عطية، 1996، ص.17)، وبالتالي فإن الفنان لا يسجل شيئاً جاهزاً ولكنه يرى في ذلك محاكاة وموضوعاً للبحث يخضعه لأسلوبه الخحاص، فصياغة الفنان الموضوعية قد خلقت فيه واقعة جديدة بتعبيرها.

وهذا لعله سبب الخلط الذي يمدث بين الجمال الطبيعي والجمال الفني لدى الكثيرين عندما يقوم الفنان برسم لوحات المناظر الطبيعية الخلابة أو ما يعبر عنه الشاعر أو

1 كلايف بل Clive Bel (1881-1964)، ناقد في إنجليزي الجنسية، مهتم بالشكليات وتطور نظرية الفن. 2 زيوكس Zeuxis، رسام إيطالي ولد عام 464 ق.م، اشتهر بالرسم التصويري لآلمة. 
الكتاب عندما يصف جمال الطبيعة وسحرها، ولكن ما يميز ذلك هو أن الحكم على جمال الطبيعـة وتقييمها لا يتم إلا مـن خـلال الأعمـال الفنيـة التي تضفي إليها وبتعلها ذات مضمون ومعنى. وهذا على حد قول شارل لالو Charles Lalo 1 C "الطبيعة ليست لها قيمة استيطيقية إلا عندما ينظر إليها من خلال فن من الفنون" (لالو، 1959، ص.7). كما أن علم الجمال لا يتخذ من الجمال الطبيعي موضوعاً له إلا حينما يكون هذا الجمال معروضاً من خلال رؤية فنية إنسانية، فالموضوع الحقيقي المباشر لعلم الجمال هو القيم الجمالية في الأعمال الفنية وليس في الطبيعة، على هذا فإن الفن هو تحليل أو تحوير الإنسان للمواد الطبيعية وإعادة صياغته ومن خلاله وبأسلوبه الإنساني الفردي، أو حسب ما يقول بيكون أن الفن هو الإنسان مضافاً إلى الطبيعة. فمن خلال التعبير الفني يكتسب الجمال الطبيعي قيمة، ويصبح موضوعاً للتذوق الفني ولذلك يمكن أن يقال إن موضوع الجمال ليس هو الأشياء الجميلة التي ندركها بشكل مباشر بل هو أقرب إلى أن يكون تفسيراً للتعبير الجميل عن الأشياء سواءً كانت طبيعية أو

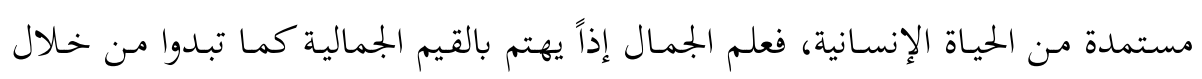
الأعمال الفنية (مطر، 1994، ص 8). ولا يمكن إدراك قيمة أي عمل فني إلا من خلال المنهج أو الطريقة الاستاطيقية لأن تذوق الفن والاستمتاع به لا يتم إلا من خلال القيمة الكامنة أو الاستطيقية للفن، ولا يمكننـا أن نفهم هـذه القيمة التي هي أهـم أنواع القيم في الفـن إلا بعـد أن نفهم الإدراك الاستطيقي الذي يجعلنا قادرين على فهمها ومن ثم نستطيع أن نفهم وندرك الموضوع الفني لذاته ونستمتع به لذاته ونتجنب الخلط بين المتعة النابعة عن قيمة جمالية خالصة وبين قيمة Charles Lalo ${ }^{1}$ 
قد تكون لأغراض أخرى متداخلة معها نفعية أو أخلاقية وغيرها (علي، 2005، ص

\section{3}

لقد اختلف النقاد والفلاسفة في تعريفهم لطبيعة القيمة الجمالية ومقاييسها، فقد يرجعون هذه القيم إلى عالم مثالي يفوق الواقع في حين يرى آخرين أهـا ترجع إلى شعور الإنسان فيما ينال إعجابنا أو تفضلنا هو الجميل والقيم، ولكن قد لا نثبت على حال قد تتبدل القيمة الجمالية بين مكان وآخر أو حتى زمان وزمان، فقد يحدث أن يعجب الناس بعمل فني معين ولا يهتمون لعمل آخر، ثم تثبت الأيام أن ماكان يعجبون به أضحى لا قيمـة لله، في حسين قد يثير إعجـابهم مـاكانوا لا يهتمـون له ويصبح مـن الأعمال النـادرة والأكثر قيمة، ولعل تاريخ الفن حافل بأمثلة كثيرة، فكم من روائع لم يقدرها أهل زماهـا التقدير اللائق بها ولم يتوصلوا إلى قيمتها الجمالية (مطر، 1994، ص. 10).

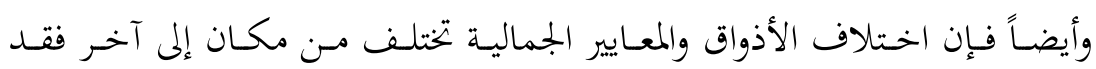
يتهافت بعض الناس على لوحة رائعة ثمينة لرؤيتها أو شراؤها بأثمان غالية، ونجد أهـا عند آخرين لا تساوي شيئاً ولا تملك أية قيمة، فما يقدره مجتمع معين لا يعني الكثير لمجتمعات أخرى. وبالتـالي فبإن إدراك الجمال وإصـار الأحكام الجماليـة لا يتم إلا مـن خـلال خبرة جماليـة نكتسـبها مـن دراسـات علم الجمـال وإن كانـت لا توجــ قواعـد صـارمة كقواعـــ الأخلاق والمعرفة العلمية يمكن أن تخضع لها هذه التجربة الجمالية، كما يصعب تقييمها في ظل معايير المنطق، ومع ذلك فقد تتفق الخبرات الجمالية في جانب الأحكام التي تصدر 
عن أصحابها وهذا يعتمد على فهم طبيعة القيمة الجمالية ومن ثم إصدار الأحكام الجمالية الموفقة.

وعلى أي حال فإن هذا لا يعني انعدام الشعور الجمالي عند عامة الناس، فالقيمة الجمالية والحلكم الجمالي ليس غائباً عندهم في كثير أو قليل، ولكن هناك فرق كبير بين أن يفهموا أو لا يفهموا القيمة الجمالية لمذه اللوحة أو أية مظاهر جمالية أخرى وبين غياب أو وجود الحكم الجمالي عندهم بإطلاق، وعندئذ يكون الإدراك الجمالي من نصيب هئلاء المثقفين أو المتعلمين وليس من عامة الناس ومع ذلك يظل لكل إنسان، مهما كان بسيطاً أن يصدر أحكاماً جمالية ويميز القبيح والجميل، وإن كان لا يصل إلى إصدار الحكم بمستوى المثقف والمتعلم كما أن هناك مجتمعات تربط الأحكام الجمالية بالأحكام الأخلاقية لديها، وبالتالي تفرض سيطرة القيم الأخلاقية على القيم الجمالية، وتتحكم الأخلاق في الذوق الجمالي، فالمحرم واللأخلاقي والشرير لا يكون جميلاً، بينما نجد آخرون على العكس من ذلك تماماً، فهم يقولون الجميل جميل مهما كانت أحكامنا الأخلاقية نحوه. فقد يظهر الجمال مثلاً في أثر فني محرم دينياً أو مستهجن أخلاقياً كما هو الحال في معظم تماثيل الفنان الفرنسي رودان أو روايات بعض الأدباء المشاهير مثل هوجو، وبالتالي قد يهكم رجال الدين أو الأخلاقيون أو الاجتماعيون على هذه الأعمال بالرفض والإنكار لأها تدعو إلى الانحلال والفساد والاهيار الأخلاقي وظل هذا مثار خلاف دائم بين الفن

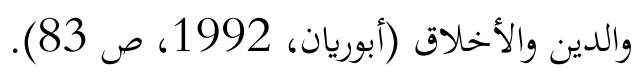
ولكن هذا الحكم الأخلاقي لا ينفي القيمة الجمالية وهذا الخلط يتشابه مع الخلط الذي يحدث بين الجميل والنافع، فقد ترفض موضوعاً ضاراً لأنه غير نافع وليس لأنه يفتقد القيمة الجمالية، فإننا يمكن أن نرفض موضوعاً مناقضاً للأخلاق لأنه كذلك وليس لأنه يفتقد القيمة الجمالية (أبودبوس، 1994، ص 114). 
إذ لاحظ الفلاسفة منـذ القـدم أننـا نربط خبرتنـا الجماليـة وهي إحساسـنا الخـاص باللـذة والمتعـة الخاصـة عنـــ إدراكنـا للأشياء الجميلـة بأحكـام معينـة، هي أحكام قيميـة، لارتباطها بقيمة معينة نقدرها لهذا الشيء الذي حكمنا عليه بأنه جميل، لكن هذا الحكم لا علاقة له عـادةً بالأمور العملية في حياتنا أو المنافع والفوائد المادية، فكأنه حكم مجرد لا يهدف إلاّ إلى المتعة غير الحسية أو الفنية ذاتا (أحمد، 2003، ص 240). ومن تم فإن القيمة الجمالية تتعين لذاتحا لا لنتائجها كما هو الحال بالنسبة للقيم الأخلاقية أو الدينية أو الاقتصادية، وبالتالي لا يمكن أن تصف الفن الجميل بالصواب أو الخطأ، وإنما نتعامل معه على أساس سلوك فني أو تعبير صادق أو غير صادق من ناحية الفنان، كما يتوجب الفصل بين القيمة الجمالية والأخلاقية ذلك لأن الفن الجميل لا يمكن أن يوضع تحت رقابة أصحاب المثل والفضائل الأخلاقية لعدم وجود صلة بتمع بينهما. وقد يحدث أن يوجه الفن إلى غايات سياسية أو اجتماعية وأيضاً دينية وهذا حدث على مر العصور، فقد استغل الفن واستخدم كأداة لترويج وخدمة أغراض وأهداف أخرى بعيدة عنه ولكنها على أية حال تظل أعمال مصطنعة تفتقد إلى القيم الجمالية وبعيدة عن الفن وليست منه في شيء. ولكن هذا قد يثير تساؤلنا عن أهمية الأعمال الفنية التي نبحث عن القيم فيها ونعتبرها مبعث وأساس القيم الجمالية فقد طرح فلاسفة الفن هذا الموضوع للتساؤل، ما هي القيمة التي ينطوي عليها الفن خاصة وإن معظم النظريات الجمالية تفترض وجود قيمة ما للظاهرة الجمالية أو الفن، فما هو هذا المفهوم وما هي غايته؟ 4.3 نظراً لتعدد مفاهيم وتعريفـات الفن تبعاً لآراء الفلاسفة واختلاف ووجهات النظر كل حسـب رؤيته والاتحاهـات والمـذاهب التي ينتمسي إليها، وبالتـالي فإنـه مـن الصعب ركب 
الإحاطة بمفهوم خـاص ومحـد ويمكـن أن يصف أو يعرف هـذه الظـاهرة أو هـذه القيمـة الإنسانية بشكل ومضمون كامل وشامل يعبر عن حقيقة الفنون كلها.

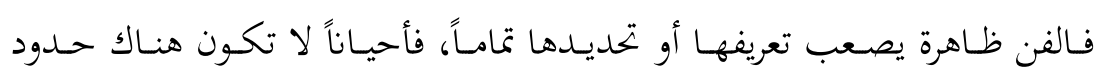
واضحة بين ما يمكن اعتباره فناً، وما لا يمكن اعتباره كذلك، وما قد نعتبره اليوم فناً قد لا يصبح كذلك بعد حين من الزمن، وهذا تبعاً للاهتمامات الشائعة وأساليب الحياة المتغيرة والمتطورة في كل عصر. ومـا زاد الأمـر تعقيـداً أن هنـاك تصـيفات عديـدة للفنـون مـن الصـعب حصـرها وتحديدها هي الأخرى، فقد تداخلت إن لم نقل تضاربت المفاهيم بين ما هو فن بالفعل حسب مـا هو معروف في التصنيفات الفلسفية أو الأكاديمية بشكل عام، وبين مـاكان يعتبر خارج عن مجال الفنون، واعتبر دخيلاً عليها مثل فنون الأزياء والموضة وفنون الطهي أو الفنون الرياضية الاستعراضية، وما شابه من الموضوعات التي تخطت الحدود وتسببت في الخلطط والتداخل بين مـا هو فن ومـا هو غير ذلك، فهذا التنوع في ججالات الفن جعل إمكانية وضع تعريف محدد لمصطلح الفن ليس بالأمر الهين، ولكن ما زاد في الأمر صعوبةً

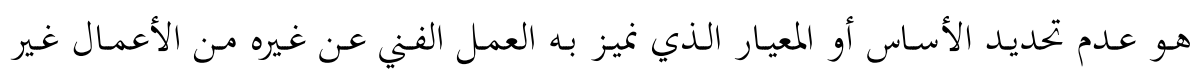
الفنية.

\section{3}

لقد تطورت كلمة الفن Art عبر التاريخ وأخذت معانٍ مختلفة حسب الهدف أو الغرض الفني أو النظرة التي تكمـن خلف معنـاه، ولعل أبرز الأسباب لعدم إمكانية أو صعوبة تحديد مفهوم محدد للفن لأنه نشاط إنساني لا يخضع للأحكام المطلقة ولا يعرفها 
ولا يتقيد بزمان ولا مكان، فهو نشاط يتسم بعدم الثبات ومتغير على الدوام وسريع التطور

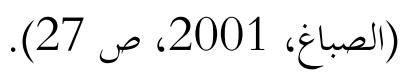

وإذا مـا بحثنـا عن معنى هذا المصطلح بدايةًة في اللغـة فبإن كلمة فن في اللغـة تعني

حسب مـا ورد في القـاموس المحيط (لغة الحال والضرب مـن الشيء أي أنه نوع ما) (بن يعقب، ص 258). (25). وأما في اللغة الإنجليزية فإن كلمة فن تعني Art وهو ذات المعنى في اللغة الفرنسية،

$$
\text { وهذا يرجع إلى الأصل اللاتيني لها وهو : Ars. }
$$

والفن بالمعنى العام جملة من القواعد المتبعة لتحصيل غاية معينة مثل الجمال أو الخير

أو المنفعة وبالتـالي فإنه وفقاً لهذه الغايات يتم تحديد التسمية، فإذا كانت الغاية من الفن تحقيق الجمال سمي الفن بالفن الجميل، في حين يطلق على الفن بالصناعة عندما تكون غايته المنفعة والفائدة للإنسان (صليبا، 1982، ص 165). والواقع لـو أنــا بحثنـا في أصل كلمـة الفـن منــ العهـد اليـوناني القــيم، فإنـا تعني باليونانيـة وهـو مـا يمثـل النشـاط الصـناعي النـافع بشـكل عـام المتمثـل في Techne الصناعات المهنية والمهارات اليدوية كالنجارة والحدادة والزخرفة والعمارة وما شابه، إضافة إلى باقي الفنون الاعتيادية الأخرى مثل النحت والرسم والموسيقى وغيرها من الفنون الجميلة

$$
\text { المتنوعة (إبراهيم، 1977، ص 8) 8). }
$$

وفي اللغات الأوروبية الحديثة خرج عن الكلمة اليونانية المصطلح Technology ويقصد بـه الصناعة أو التقنيـة الصناعية، في حسين خـرج عن المعنى اللاتيني كلمـة Art، واقتصر استخدامها في تسمية الفنون الجميلة المتخصصة مثل النحت والرسم والموسيقى ليق والشعر وغيرها. 
ولعل هذا الخلط بين الفنون الجميلة والتطبيقية عند اليونانيين جعل "أرسطو" يرى

الفن مساوياً للصناعة أو الحرفة، أما المحاكاة فكان يقتصرها على الفنون الجميلة. وإذا كان لا وجود للتمييز بين الفنون الجميلة التطبيقية في تلك العصور القديمة فإن "دانتي" و "توما الاكويني" يخالفان ذلك المعتقد فقد رأى القديس "توما" أن صناعة الأحذية والطبخ وفن الشعوذة والنحو والحساب ليست أقل من الفنون. وهناك آخرين أيضاً يفرقون بين الفن والمهن، فيقولون أن الفن نشاط تلقـائي حر بينما المهن صناعة مأجورة وهذا على غرار رؤية كانط الذي يرى الفن لا يرتبط بالمنفعة أو الفائدة في حين أن المهن أو الصنعة عمل نفعي غايته الفائدة والمصلحة (خضر، 2004،

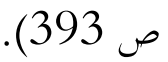

وإن كـان الكثير مـن فلاسفة الجمال فيمـا بعـد فرقوا بـين الفنون الجميلة والفنون التطبيقية أو النفعية فإننا نجد لاحقاً أن جون ديوي على العكس من ذلك، فهو يؤكد على لي العلاقة الوثيقة بين كل تلك الفنون ويجمع بين الأنشطة الصناعية والفنية التي تمثل النافع والجميل على السواء، كذلك يبين سوريو في مستقبل علم الجمال، التشابه الواضح بين الفن والصناعة وفرق بين الشكل العملي والشغل الفني وبالتـالي يتوجـب التعامل مع الفن إلى جانب الصناعة على السواء في توزيع الشغل الاجتماعي فإذما لا يختلفان، وهناك من يرى أن الفن ابتكار والصناعة منتجة، والفن هو روح الصناعة الفائقة (خضر، 2004، ص

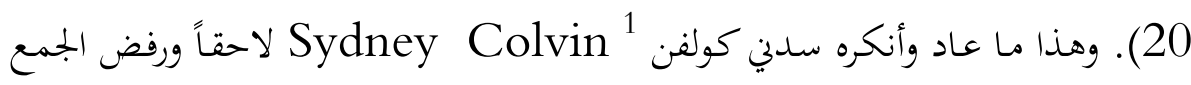
بين تلك الفنون التي تمدف إلى المتعة والتأمل وتلك الفنون النفعية (خضر، 2004، ص

1 سدني كولفن Sydney Colvin 
وبالنظر في معجم "لالاند" نجد تعريف الفن على صورتين:

صورة عامة، وتعني مجموع العمليات التي تستخدم مادة للوصول إلى نتيجة معينة، والصورة الخاصة، وهي الصورة الجمالية الاستاطيقية. وأنه عملية إبداعية تهدف إلى غايات استاطيقية مثلما يهدف العلم إلى غايات منطقية (La Land, 1947, PP 77-78). ويقول يوهان فردريك شيلر 1859-1905 أن الفن نشاط حر، وربط بين الفن واللعب على أساس أن الفن يرادف الحرية، ويقول إن الفن لا يبلغ الحقيقة إلا عندما ينقطع تماماً عن الواقع ويصبح مثالياً تماماً، وبذلك فصل الفن عن سائر الأنشطة العملية الأخرى التي يمارسها الإنسان (الصباغ، 2001، ص 35). 6.3

لقد ميز العديد من فلاسفة الفن والجمال بين الأشياء النافعة والأشياء الجميلة وتلك التي تحقق لنا التسلية واللهو الأشياء الجميلة، وكانت الأشياء الجميلة تحظى بالمقام الأرفع والقيمة الأعلى مـن هذه الأشياء، إذ نرى الكاتب الفرنسي جويتيه The Gautier يقول بتعارض الجمال مع المنفعة ليس من جميل حقاً إلا ما خلا تماماً من أي غرض، فإن كان مـا هو نافع لابد بالضرورة مـن أن يكون ذميماً (إبراهيم، 1973، ص 117). وبالمقابل هناك ابتحاه مغاير لا يؤمن بأهمية القيمة المطلقة للفن وإنما يرجع أهميتها لارتباطها باللذة واللعب والمنفعة أو يقلل من قيمتها لعدم تقيدها وخضوعها لقواعد العقل والمنطق

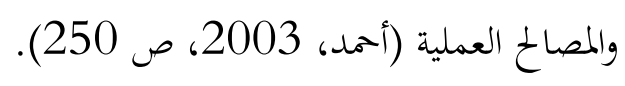

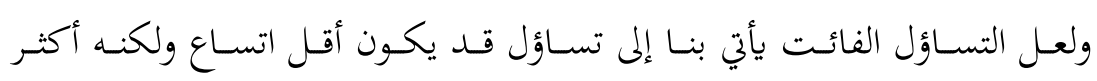

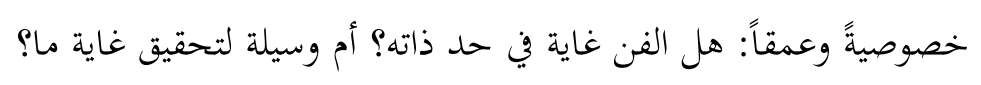


قد تكون الإجابة مقنعة إذا ما تعاملنا مع الفن على أنه فن وليس شيئاً آخر غيره، ولا نبحث في الفن عن قيمة غير قيمة الفن في ذاته وهذا هو ابتحاه أصحاب نظرية الفن للفن بمعزل عن متطلبات الحياة النفعية والمادية ودون ربطه بالجوانب الأخلاقية أو التربوية والسياسية ولا حتى الدينية.

وبالمقابل هناك من يرى غير ذلك، فهو وسيلة لتحقيق غاية، فالفن بالنسبة لهم يلعب دوراً في الحياة ويرجعون أهميته إلى الدور التربوي والأخلاقي وقدرته على ترسيخ القيم والفضائل بـين النـاس أو لحندمة أغراض وطنيـة أو سياسية ودينية كما حسدث في العصسور الوسطى إبان سطوة وسيطرة الكنيسة، ولازال الفن يعاني ويكابد من مثل هذه الظواهر وإن كان بأقل حدة، وأيضاً فإن أصحاب هذا الاتحاه لا يهملون الدور النفسي وتحقيق المتعة والراحة وإشباع الحاجات النفسية والروحية لدى الإنسان، فهي وإن كانت حاجات غير مادية ولكنها أساسية فهو يحقق نظرة هؤلاء للفن بأنه وسيلة لتحقيق غاية ما في الحياة الإنسانية وبالتالي تحقق أهمية وقيمة الفن تحت شعار الفن من أجل الحياة وليس ما يسمى بالفن للفن. وإذا ما أخذنا المفاهيم عامةً أو الاتجاهات الأساسية للرؤية الفنية وبشكل عام فإننا نجد بعض الفلاسفة يـرون أن الفـن تعبير عن العاطفة وبالتـالي فإن أي عمل فني لا يثير عواطفنا أو يحرك مشاعرنا لا يعتبر جميلاً، وبذلك ميزوا بين فن يثير العاطفة أو آخر يعبر عنها وبين فن يهقق الشروط الفنية وينبع من القدرة الخلاقة وبإمكانه تحقيق أكبر قدر من الإمكانيات الفنية داخل العمل الفني. وهناك فلاسفة آخرون يعتقدون بعلاقة الفن بالحلم أو العاطفة والخيال، ويعتبرون الفن هو وسيلة تنقلنا إلى عالم الخيال والأحلام باعتباره العالم الآخر الذي يتقابل مع حياة

$$
\text { الواقع وعالم الحقائق (خضر، 2004، ص ص 39-40). }
$$


ولاحقاً في فلسفة القرن التاسع عشر يمكن ملاحظة أمثلة للخلط بين الفن والدين والفلسـفة كمــا هـو عنـــ "هيجــل" Hegel و "شـيلنج" Schelling و "برجسـون" Bergson بالتاريخ والوثائق على يد الفرنسيين وكذلك كروتشه، وأيضاً خلط الفن مع الرياضيات عند

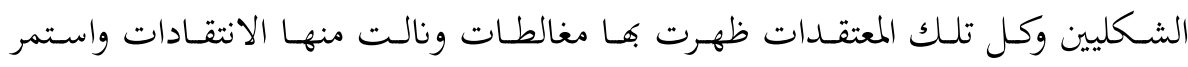
التساؤل والبحث في عقل الإنسان عن ذلك العالم من الخيال النقي الخالي من الشوائب وبدون تلك الحقائق الفلسفية والتاريخية والدينية وبدون القيم الأخلاقية والنغعية. وقد أجمع الفلاسفة على أهمية علم الجمال كعلم قائم بذاته يختص بدراسة تفسير الجمال والفن والطبيعة ودراسة هذه الظاهرة باعتبارها قيمة جمالية خالصة وإن كان أغلب الفلاسفة يستبعدون الطبيعة من هذه الدراسة لأن علم الجمال وفلسفته تبحث في الشكل والمضمون للأعمال الفنية وما تحمله من معانٍ وتعبير عن المشاعر والأحاسيس الإنسانية في حين أن الطبيعة صامتة وتخلو من أية مضامين ولا دخل للإنسان فيها إذ يعتبرها البعض مجلي الإبداع الإلهي، ويكمن جمالها في محاكاة الفنان لها فهي مصدر الهامة وإبداعه، وبراعة الفنان بتعل من لوحات الطبيعة صوراً رائعة ومعبرة. وبالتالي فإن الأعمال الفنية تستمد قيمتها ليس من خلال القياسات الخارجية ولكن لجدارقا أو قيمتها الجمالية بذاتا، فالفن لا يعبر عن شيء سوى ذاته ولذلك فإن الأعمال الفنية لا يمكن تقييمها وإصدار الأحكام عليها إلا بالمعايير الجمالية وعدم إخضاعها لأية مقومات أخرى مثل الدين أو السياسة، وعدم ربطها بقيود اجتماعية أو أخلاقية وما شابه حتى يتسنى للفن التحرر وتحقيق أهدافه. 


\section{4- - 2 - الخاتمة وأهم النتائج:}

مما تقدم عرضه يمكن أن نخلص إلى النتائج التالية: 1- علم الجمال (استاطيقا Aesthetices) هو العلم أو الدراسة المتعلقة بفهم وإدراك الجمال فيما يقوم به الأشخاص من إبداع في مختلف مجالات الفنون، وتقديم مناهج لدراسة الفن والجمال وعلاقته بالإنسـان ومشـاعره وإحساسه ومـدى تأثره بالجمال. كما يختص بتقييم الأعمال الفنية وإصدار الأحكام الجمالية عليها. 2- اختلف فلاسفة الجمال في إيجاد تعريف جامع للفن وفي تحديد معايير محددة لتقييم الأعمال الفنيـة إلا أهمم اتفقوا على وضع شروط وأصول يمكن الاسترشـاد بهـا وتطبيقها لتذوق ومعرفة الجمال وتحديده وتقييمه وإصدار الأحكام الفنية والجمالية عليها. 3- كمـا اختلف الفلاسفة والمفكرون في وضع المعايير الجمالي الاستاطيقية مـن حيـث خضوعها لأية مقومات أخرى مثل الدين والسياسة مع عدم ربطها بأية قيود اجتماعية أو أخلاقية، وأن يكون "الفن للفن". 4- يظل من الصعب فهم وإدراك الأعمال الفنية إلا من خلال المناهج الاستاطيقية للفن، ويمكن التمييز بين الجمال الطبيعي والجمال الفني، فالأول هو الشيء الجميل، والثاني هو العمل الجميل، أي خلق الخالق، وإبداع البشر، بينما الجليل لا يمكن إدراكه أو رؤيته ويظل في نطاق فكرنا في الجمال اللامتناهي، وغالباً ما يحظى بنصيب أوفر لدى فئات المثقفين والمتعلمين، فيما يضمحل لدى العامة من أفراد المجتمع، ولكن يظل لكل فرد حظوة تزيد وتنقص أن يستشعر الجمال ويميز ما بين الجميل والقبيح، وليس أدل من ذلك اهتمام ورقي المجتمعات المتقدمة والمثقفة بالفن والمظاهر الجمالية. 


\section{المراجع}

أولا: المراجع العربية: - أن

إبراهيم، زكريا. (1973). الفنان والإنسان، القاهرة: مكتبة غريب. إبراهيم، زكريا. (1977). مشكلة الفن، القاهرة: مكتبة مصر. (1994). الفنان ولانسان، الفادة: مكية غريب.

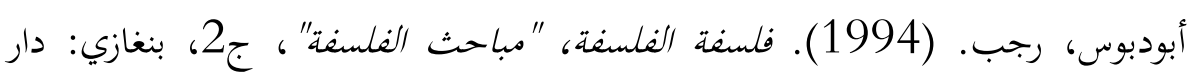
الكتب الوطنية.

أبوريان، محمد علي. (1992). فلسفة الجمال ونشأة الفنون الجميلة، ط8. الإسكندرية: دار المعرفة الجامعية. أحمد، عزمي طه السيد. (2003). الفلسفة مدخل حديث، عمان: دار المناهج للنشر والتوزيع.

أفلاطون. (1965). محاورة فيدون. ترجمة: علي سامي النشار. القاهرة: دار المعارف.

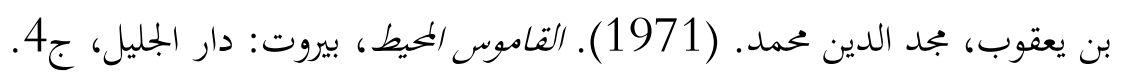

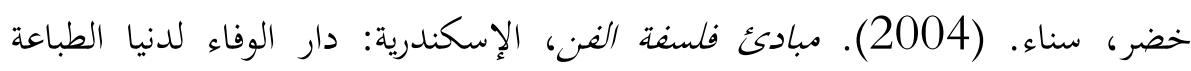
والنشر.

الديدي، عبد الفتاح. (1981). علم الجمال، القاهرة: مكتبة الأنجلو المصرية.

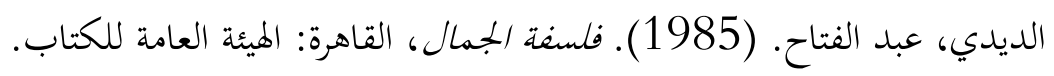

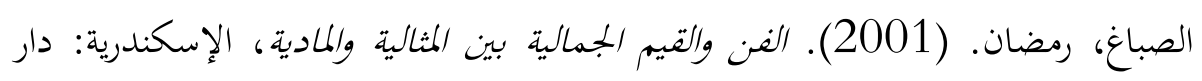
الوفاء لدنيا الطباعة والنشر.

صليبا، جميل. (1982). المعتم الفلسفي، بيروت: دار الكتاب اللبناني، ج2.

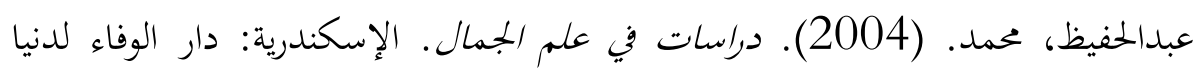
الطباعة والنشر. عبد الحميد، شاكر . (2001). التفضيل الجمالي، الكويت: مطابع الوطن العربي.

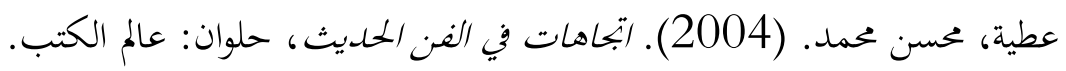


عطية، محسن محمد. (1996). غاية الفن. ط2. دار المعارف بمصر.

علي، حسين. (2005). فلسفة الفن رؤية جديدة، القاهرة: الدار المصرية السعودية للطباعة والنشر والتوزيع.

لالو، شارل. (1959). مبادئ علم الجمال، ترجمة: مصطفى ماهر، القاهرة: دار إحياء الكتب العربية. - ماك.

مجاهـد، مجاهـد عبــ المـنعم. (1980). دراسـات في علــم الجمــال، القــاهرة: مكتبـة الأنجلوالمصرية.

مطر، أميرة حلمي. (1994). علم الجمال وفلسنة الفن. ط2. القاهرة: دار المعارف. ثانيا: المراجع الأجنبية: - م

Kant. (1790). Critique of Judgmnt. Transleted with introduction and notes by Bernard, J.N. Macmillan comp.L.T.D. London.

La Land (1947). Vocbulaire techniqueet critique de La philosophie. p.u.f, Paris, 5éd 1947 (Article "Art") p.p. 77-78. 